\title{
Secukinumab Reduces Endothelial Dysfunction in Subjects With Moderate-to-Severe Plaque Psoriasis Over 52 Weeks: Results of the Exploratory CARIMA Study
}

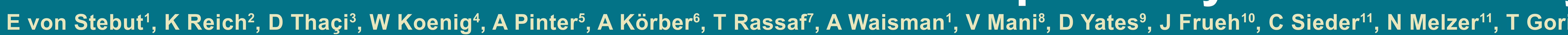

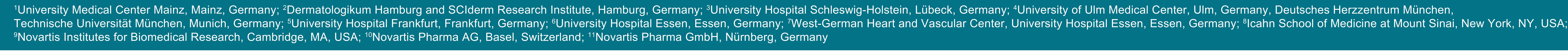

\section{ABSTRACT}

Introduction: An increased incidence of cardiovascular (CV) events has antibody that selectively neutralizes IL-17A, has significant efficacy in moderate-to-severe psoriasis and psoriatic arthritis. CARIMA explored the effect of secukinumab on $\mathrm{CV}$ risk markers in psoriasis.

Methods: CARIMA was a 52-week, multicenter, exploratory, randomized, moderate-to-severe plaque psoriasis but without manifest CV diseases wer moderate-to-severe plaque psoriasis but without manifest CV diseases were
eligible. The primary outcome measure was endothelial function, a marker of early atherosclerosis, measured by flow

Results: 151 subjects (mean age 45 years, $68 \%$ male) were randomized. espectively and 26 and 23 subjects received placebo followed by $300 \mathrm{mg}$ or $150 \mathrm{mg}$ secukinumab, respectively. A baseline FMD (mean \pm SD) of $4.6 \%$ assigned to 300 or $15 \%$ mg seckin 3 mab or (lacebo followed by $300 \mathrm{mg}$ or $150 \mathrm{mg}$ secukinumab At week 12, the baseline-adjusted FMD showed a numerically larger improvement in subjects receiving $300 \mathrm{mg}$ secukinumab vs. the pooled placebo group $(\Delta=1.2 \%, \mathrm{Cl}[-0.7 ; 3.1], P=0.223)$ than $(\Delta=0.8 \%$, Cl [ [-1.0; 2.6], $P=0.403)$. At week 52, FMD was increased by $2.1 \%$ in subjects receiving $300 \mathrm{mg}$ secukinumab $(\mathrm{Cl}[0.8 ; 3.3], P=0.002$ ) and by $2.1 \%$ in subjects receiving $150 \mathrm{mg}$ secukinumab $(\mathrm{Cl}[0.7 ; 3.4], P=0.003)$ vs. baseline. There were no deaths and no myocardial infarctions in the study.
There was one case of a cerebral infarction, which was not suspected to be related to study medication.

Conclusions: Atthough subjects with established CV diseases were indings of endothelial dysfunction associated with subclinical atheroscleros in psoriasis. A numerical, clinically meaningful improvement of FMD was statistical significance after 52 weeks ( 150 and $300 \mathrm{mg}$ ). The safety profile of secukinumab was comparable to prior studies and there were no new safety
signals. Secukinumab may improve endothelial function, which could help to prevent cardiovascular disease progression in psoriatic subjects.

\section{INTRODUCTION}

An increased incidence of $\mathrm{CV}$ events has been reported in psoriasis patients This comorbidity could be the result of a prolonged subclinical systemic This comorbidity could
inflammatory response
Secukinumab, a fully human monoclonal antibody that selectively neutralize
interleukin (LL)-17A, has shown significant efficacy in the treatment of moderate-to-severe psoriasis and psoriatic arthritis, demonstrating a rapid
onset of action and sustained response with a favorable safety profile' Previous studies have shown tha
$13 \%$ relative $\mathrm{CV}$ risk reduction ${ }^{2}$

CARIMA aimed to explore the effect of secukinumab on $\mathrm{CV}$ risk markers in

\section{METHODS}

CARIMA was a multicenter, exploratory, interdisciplinary, randomized,
double-blind, placebo-controlled trial (NCT02559622). Only subjects with moderate-to-severe plaque psoriasis and without known severe CV diseases were eligible

- They were randomized in a 2:2:1:1 ratio to $300 \mathrm{mg}$ or $150 \mathrm{mg}$ secukinumab until week 52 or to placebo until week 12 followed by $300 \mathrm{mg}$ or $150 \mathrm{mg}$
secukinumab until week 52 . Placebo groups were pooled for week 12 secukinumab
comparisons

The primary outcome measure was
atherosclerosis, measured by FMD

Experienced sonographers were trained and certified to measure FMD wir a standard protocol, equipment, and software. FMD values of 49 volunteers (not study subjoc
reproducibility

The subject's arm was immobilized using a pneumatic pillow and brachial cuff to $220 \mathrm{mmH}$ H f f $5 \mathrm{~m}$ minutes and for 4 minutes following deflatition. FMD was
measured as the \% maximal increase in diameter following deflation of the cuff Data were assessed by cardiologists at a reading center for quality control

\begin{tabular}{|c|c|c|}
\hline \multicolumn{3}{|c|}{ Figure 1. CARIMA Study Design } \\
\hline \multicolumn{2}{|c|}{$\begin{array}{l}\text { Baseline } \\
\text { Ine }\end{array}$} & \\
\hline & $\begin{array}{l}\text { Secukinumab } 300 \mathrm{mg} \\
(\mathrm{BSL} ; \mathrm{Wk} 1,2,3,4,8)\end{array}$ & $\begin{array}{l}\text { Secukinumab } 300 \mathrm{mg} \\
\text { (Wk k } 12 \text { and } 4 \text { quwk) }\end{array}$ \\
\hline & $\begin{array}{l}\text { Seculkinumab } 150 \mathrm{mg} \\
\left(B S L ; W_{k} 1,2,3,4,8\right)\end{array}$ & 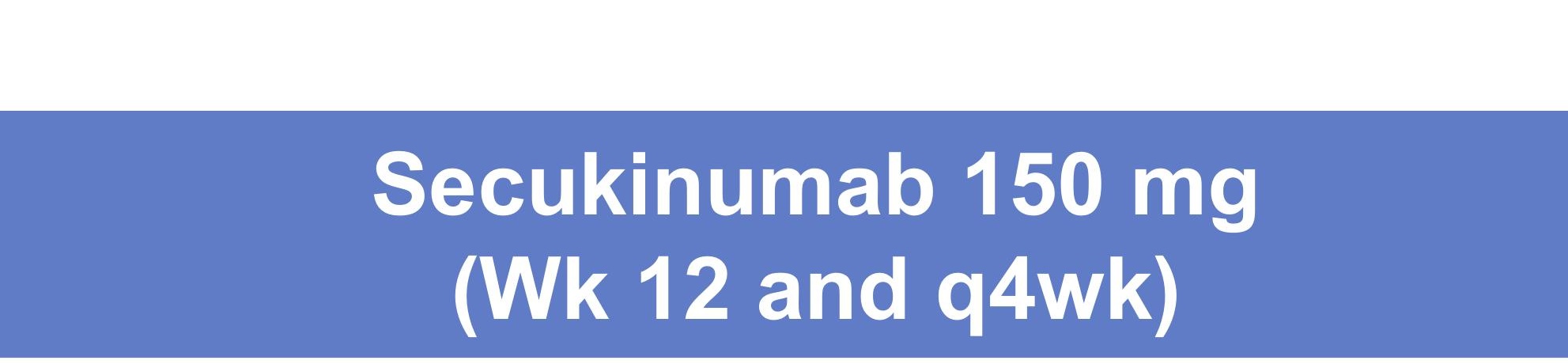 \\
\hline & $\begin{array}{l}\text { Placebo } \\
\text { (BSL; } 1,2,3,4,8)\end{array}$ & 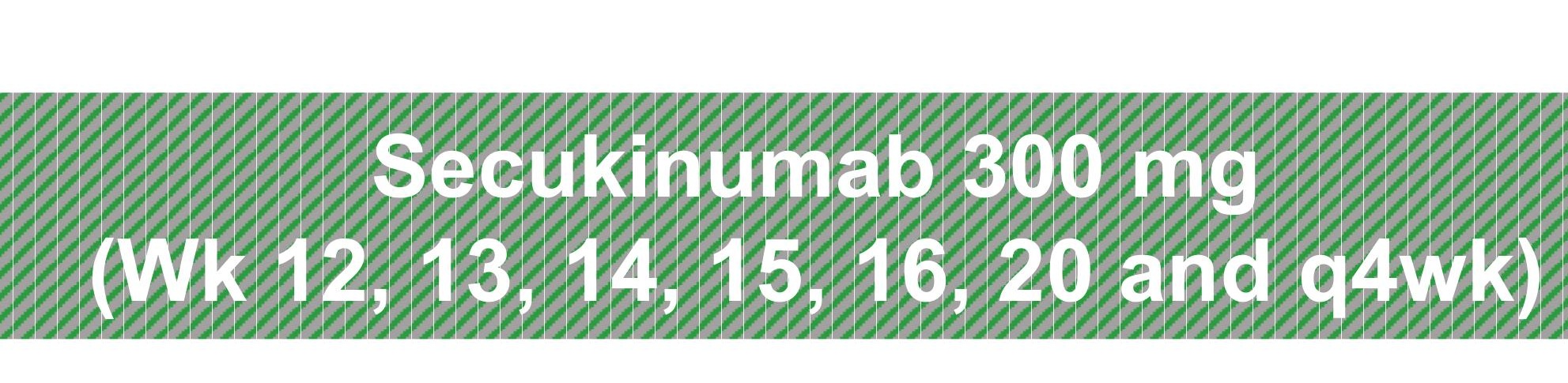 \\
\hline & $\begin{array}{l}\text { Placebo } \\
\text { (BSL; Wk 1: }\end{array}$ & (Wvis: \\
\hline
\end{tabular}

RESULTS

\begin{tabular}{|c|c|c|c|c|}
\hline & $\begin{array}{c}\text { A. } \\
\operatorname{SEC} 300 \mathrm{mg} \\
(\mathrm{n}=48)\end{array}$ & $\begin{array}{l}\mathrm{B}^{\mathrm{B}} \\
\mathrm{SEC}(150 \mathrm{mg} \\
(\mathrm{n}=544)\end{array}$ & 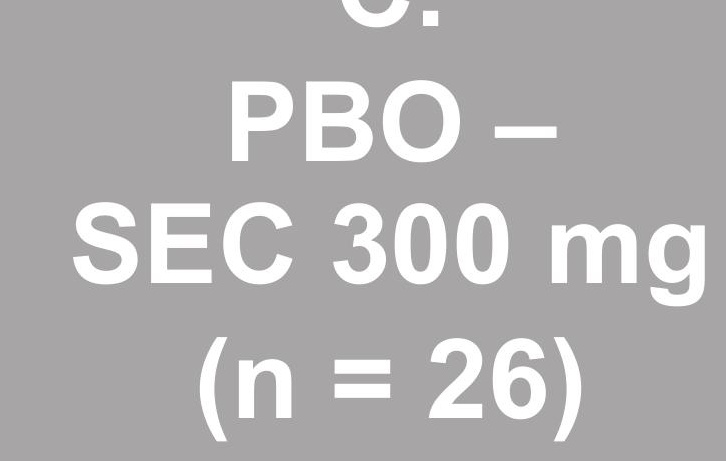 & $\begin{array}{c}\mathrm{PBD}- \\
\text { SEBC } 150 \mathrm{mc} \\
(\mathrm{n}=23)\end{array}$ \\
\hline In age, years (SD) & $44.2(12.9)$ & $46.0(14.4)$ & $43.7(11.4)$ & $46.8(13.1)$ \\
\hline gender, $n(\%)$ & (77.1) & 31 (57.4) & $18(69.2)$ & $16(69.6)$ \\
\hline vwe & 86.5 (15.3) & $84.4(19.3)$ & $95.4(26.0)$ & $89.8(22.0)$ \\
\hline$(\mathrm{kg} / \mathrm{n}$ & 27.8 & 28.1 & 30.1 & 29.7 \\
\hline seline PASI, mean (SD) & $19.3(7.9)$ & $21.7(10.5)$ & $17.5(4.2)$ & $19.5(6.1)$ \\
\hline $\begin{array}{l}\text { Mean time since psoriasis } \\
\text { diagnosis, years (SD) }\end{array}$ & $20.6(12.7)$ & $20.8(13.3)$ & $18.9(11.7)$ & $20.3(11$ \\
\hline Psoriatic arthritis reported, n (\%) & 12(25.0) & $15(27.8)$ & $4(15.4)$ & $4(17.4)$ \\
\hline $\begin{array}{l}\text { Prior non-biologic, systemic } \\
\text { therapy, } \mathrm{n}(\%)\end{array}$ & $43(89.6)$ & $46(85.2)$ & $24(92.3)$ & .6) \\
\hline Prior biologic therapy, $\mathrm{n}(\%)$ & 15 & .0) & $8(30.8)$ & 9 (39.1) \\
\hline betes, $n(\%)$ & & 年 & $3(11.5)$ & \\
\hline Dyslipidemia/ / & 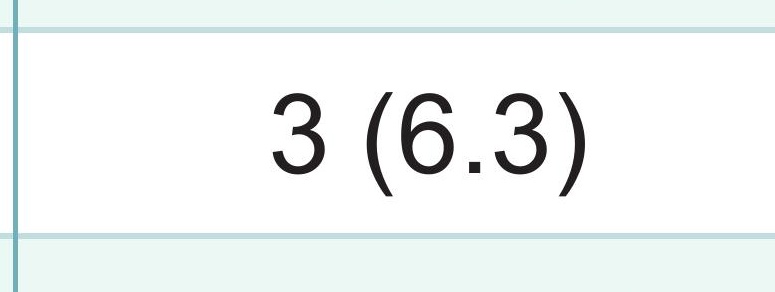 & $3(5.6)$ & $5(19.2)$ & $1(4.3)$ \\
\hline n. n & 13 & $14(2$ & (34.6) & (30.4) \\
\hline noking & 19 & 21 & $11(42.3)$ & (39.1) \\
\hline & & & & \\
\hline noking status, & $20(41.7)$ & 0.7) & i.2) & $7(30.4)$ \\
\hline
\end{tabular}

At week 12, the baseline-adjusted FMD showed a numerically larger improvement in subjects receiving $300 \mathrm{mg}$ secukinumab vs. the pooled placebo group $(\Delta=1.2 \%, C 1-0.7 ; 3.1], \mathrm{p}=0.223)$ han in subjects receiving $150 \mathrm{mg}$

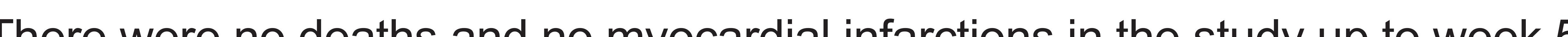
There was one case of a cerebral infarction after surgery for ovarian cancer
in a 67 -year-old hypertensive subject who had received $150 \mathrm{mg}$ secukinumab
for 94 days, which was not suspected to be related to the study medication Figure 2. Baseline FMD

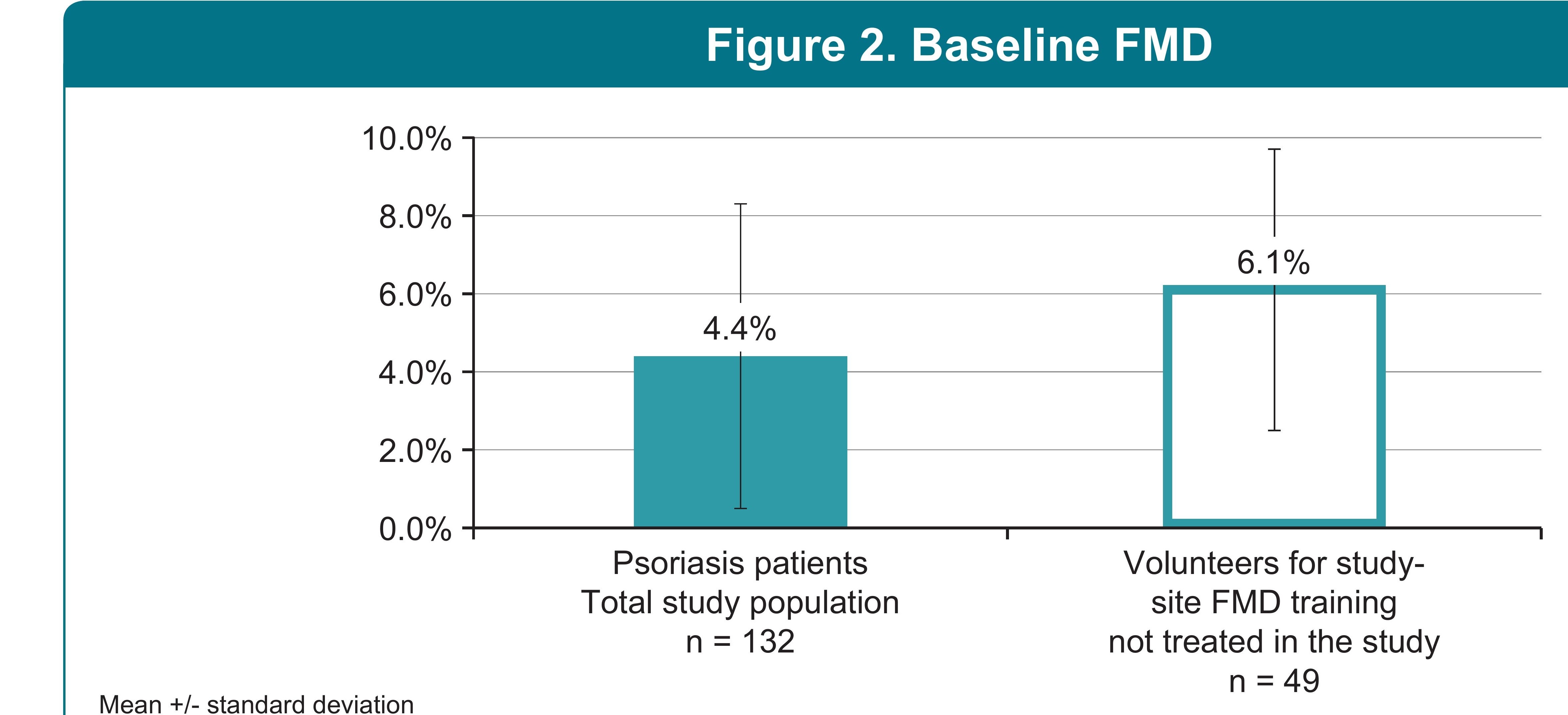

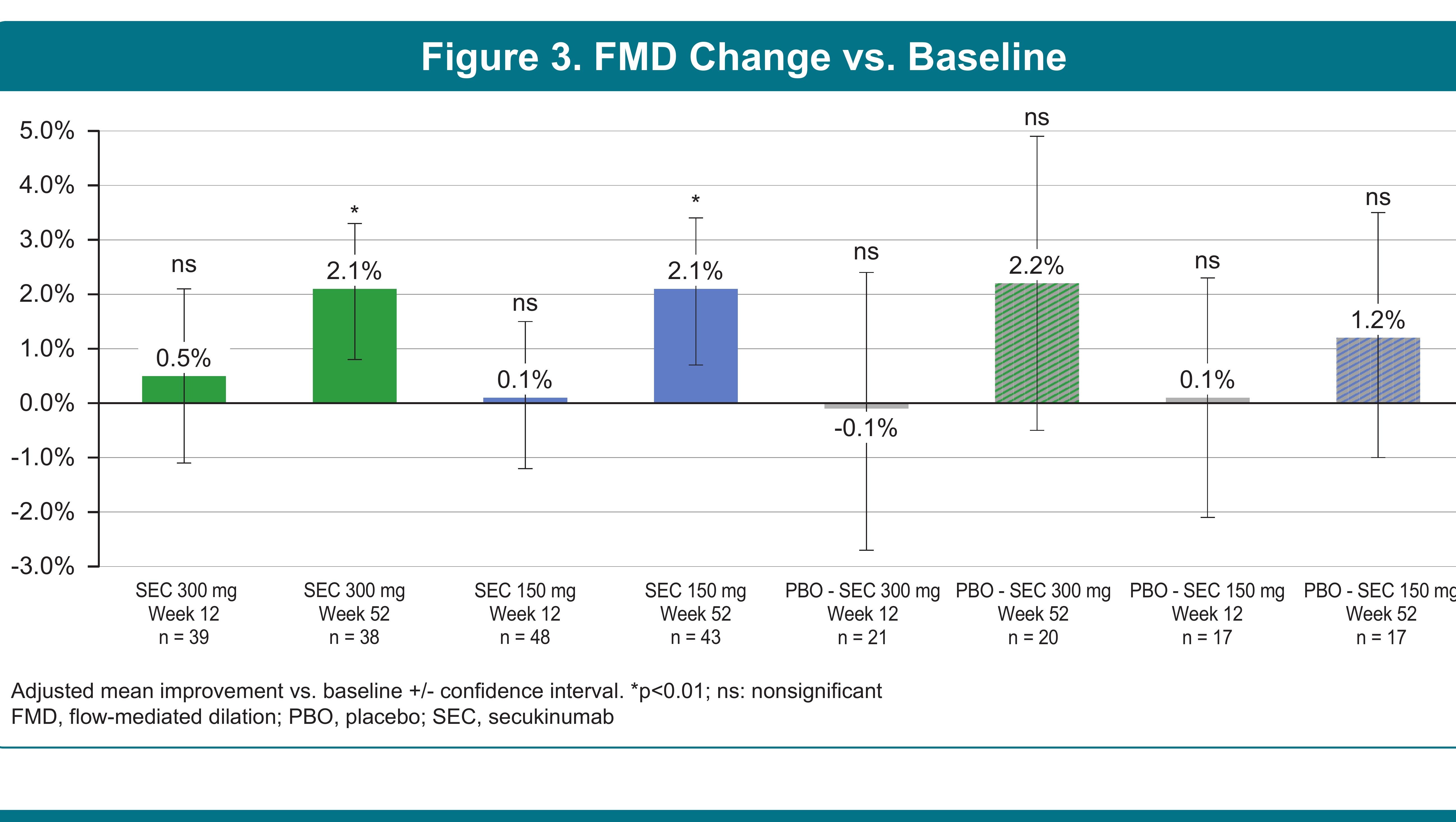

CONCLUSIONS

Although subjects with known severe CV diseases were excluded, the comparably
large CARIMA study population confirmed associated Win subcinicical atherosclerosis in psoniasis subjects The safety profile of secukinumab was comparable to prior studies and there were A numerical, but clinically meaningful, improvement in FMD (> $1 \%$ ) was observed
after 12 weeks (secukinumab $300 \mathrm{mg}$ ). The difference reached statistical signe CARIMA study results indicate that secukinumab may improve endothelial
function, thereby reducing CV disease progression in psoriatic subjects

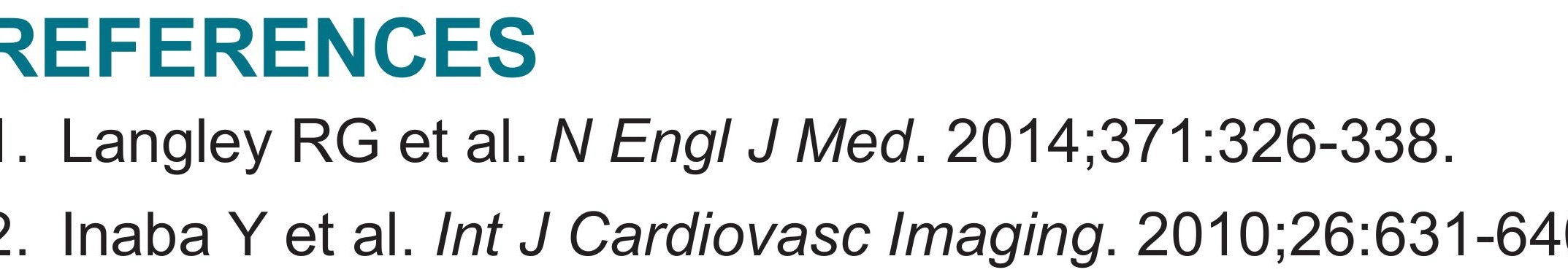

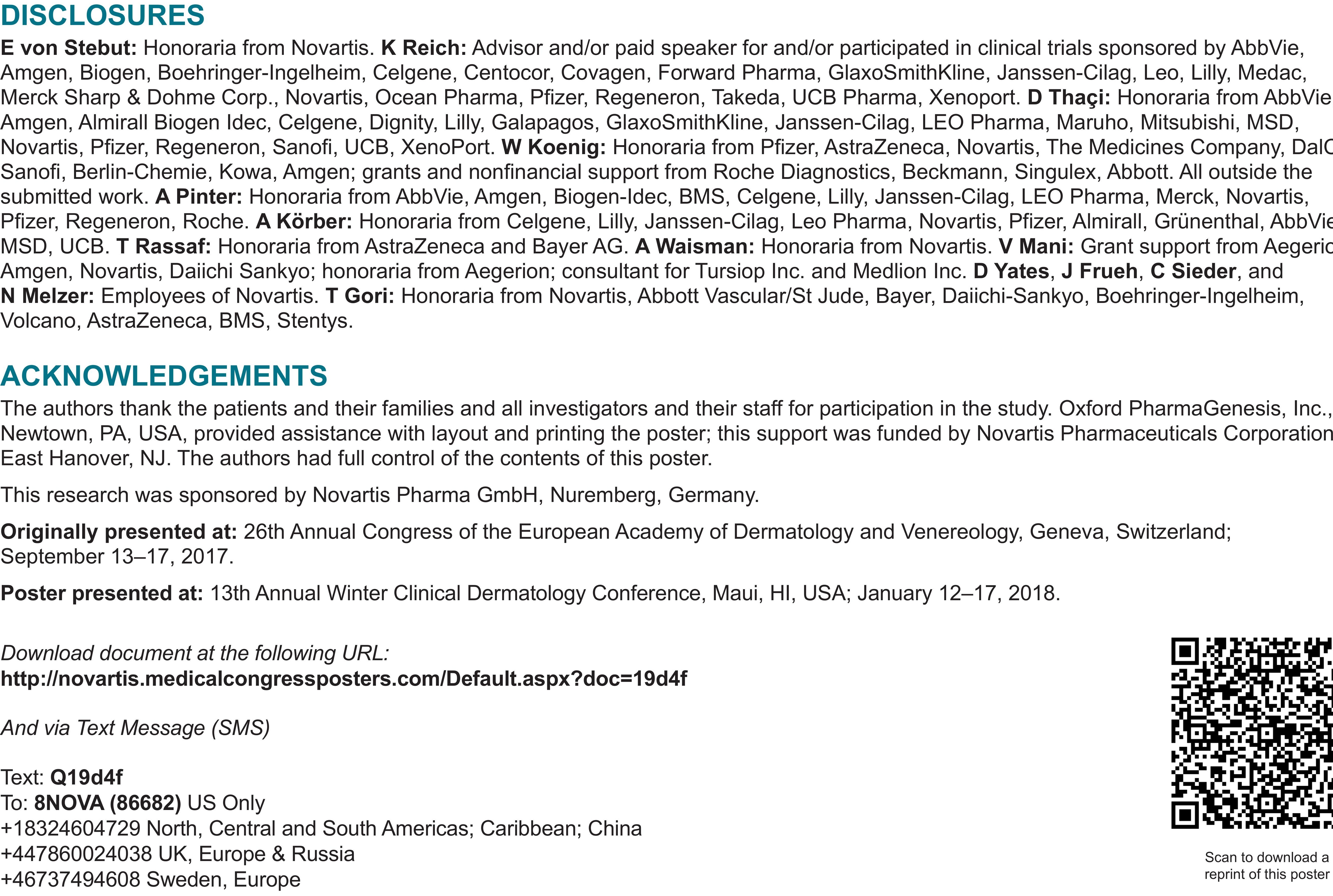

